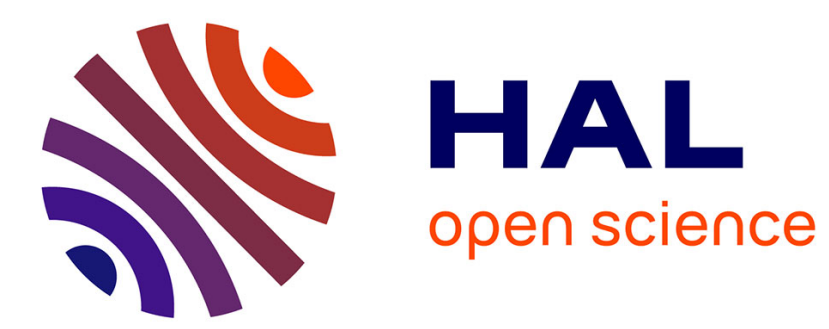

\title{
Improving NASH with a little help from thyromimetics
}

Vlad Ratziu

\section{To cite this version:}

Vlad Ratziu. Improving NASH with a little help from thyromimetics. The Lancet, 2019, 394, pp.1970

- 1972. 10.1016/S0140-6736(19)32731-X . hal-03488565

\section{HAL Id: hal-03488565 \\ https://hal.science/hal-03488565}

Submitted on 21 Dec 2021

HAL is a multi-disciplinary open access archive for the deposit and dissemination of scientific research documents, whether they are published or not. The documents may come from teaching and research institutions in France or abroad, or from public or private research centers.
L'archive ouverte pluridisciplinaire HAL, est destinée au dépôt et à la diffusion de documents scientifiques de niveau recherche, publiés ou non, émanant des établissements d'enseignement et de recherche français ou étrangers, des laboratoires publics ou privés.

\section{다)(1) $\$$}

Distributed under a Creative Commons Attribution - NonCommercial| 4.0 International 
Improving NASH with a little help from thyromimetics

\author{
Vlad Ratziu \\ Sorbonne Universités, Institute for Cardiometabolism and Nutrition, INSERM UMRS 1138 \\ CRC and Hospital Pitié-Salpêtrière, Paris, France
}

Address for correspondance : Hospital Pitié Salpêtrière, 47-83 Bd de l'Hôpital, Paris 75013, France; vlad.ratziu@inserm.fr 
Traditionally, nonalcoholic steatohepatitis (NASH) is associated with insulin resistancerelated clinical conditions, such as overweight and type 2 diabetes. Recently a quantitative association between subclinical low thyroid function and hepatic steatosis was shown both in population-based studies ${ }^{1}$ and in diabetics ${ }^{2}$, independent of metabolic comorbidities ${ }^{3}$. Incident steatosis occurs more often with higher baseline thyrotropin levels ${ }^{4}{ }^{5}$. In rodents, mild hypothyroidism increases adipose tissue lipolysis with subsequent hepatic fat accumulation; this leads to hepatic insulin resistance, increased glucose production which then exacerbates liver fat through hepatic lipogenesis 6 . Interestingly, the histological severity of both steatohepatitis and fibrosis increases with rising levels of thyrotropin, even in the sublinical or high normal range ${ }^{7}$. The findings that, in proportion to the severity of liver damage, hepatic activity of a thyroid hormone activating deiodinase enzyme is reduced, and that of a deiodinase that degrades thyroid hormone is increased, further suggests that damaged hepatic tissue is in a state of deficiency in active thyroid hormones ${ }^{8}$. This is problematic because thyroid hormones can reduce liver steatosis mainly through inducing lipophagy and restoring a healthy mitochondrial capacity ${ }^{9}$. They may also interfere with fibrogenic pathways by inhibiting TGF-beta signalling ${ }^{10}$ thus preventing fibrosis progression. In addition, they carry distinct lipid-lowering actions over a broad range of atherogenic lipoproteins such as LDLc, large VLDL, ApolipoproteinB an Lipoportein(a).

Since liver and cardiovascular disease are the main causes of death in NASH patients, thyromimetics are appealing NASH therapies, provided that the activation of the $\alpha$ isoform of the Thyroid Receptor (TR), responsible of the myriad clinical manifestations of hyperthyroidism, including tachycardia, defective bone metabolism and muscle wasting, can be avoided. Previous attempts at designing selective thyromimetics have failed, but resmetirom is a new, oral, liver-directed, highly selective TR $\beta$ agonist ${ }^{11}$.

In the current issue Harrison et al. randomized 125 patients to receive resmetirom $(N=84)$ or placebo ( $N=41)$ for 9 months. They report a profound and early reduction in liver fat content with a 
mean difference from baseline over placebo of $-22.5 \%(95 \% \mathrm{Cl}-32.9--12.2, p<0.0001)$ at 12 weeks, and a significant improvement in the pro-atherogenic lipid profile of NASH patients treated with resmetirom. Histological data showing resolution of NASH and fibrosis reduction (at least in patients with NASH resolution), two regulatory approvable endpoints, strongly favor a liver benefit; the lipid results suggest potential for cardio-vascular benefit as well. The drug was weight neutral without benefits on glycemic control. It was well tolerated, a must for long-term therapy in mostly asymptomatic patients.

These are promising and welcome results for this new class of drugs. But some limitations of this phase 2 trial must be kept in mind. The sample size was modest and the histological outcomes, arguably the most important ones for ultimate patient benefit, were only analyzed as secondary endpoints. At least half of the patients had early or no fibrosis, which, together with the short duration (under one year) could explain the lack of antifibrotic effect in the resmetirom arm. Importantly, some placebo patients with substantial weight loss were discarded from the analysis; this is understandable for exploratory purposes but reduces the overall robustness of the findings when kept in the analysis resolution of steatohepatitis was no longer significant. The authors also adopted a definition of resolution of steatohepatitis that includes an additional requirement for a reduction in an aggregate score of steatosis, hepatic cell injury and inflammation. This could favor potent antisteatogenic drugs without necessarily capturing a stronger antiinflammatory effect. Since, the results of the usual definition (dissapearance of ballooning with no or minimal inflammation, www.fda.gov/media/119044/download) are not provided, comparisons with other trials are imperfect.

Despite these limitations, Harrison et al. provide valuable insight for early drug development in NASH. They demonstrate that a reduction in liver fat content is associated with NASH resolution, thus validating this MRI-based surrogate for proof-of-concept trials. The opposite was also true, although not generalizable as it may be mechanism of action dependent ${ }^{12}$. Particularly informative is 
that hepatic fat reduction was associated with improvement in inflammation and liver cell injury, favoring the current model of lipotoxicity-mediated injury in NASH. The study also confirms that NASH resolution leads to fibrosis reversal; if this will result in less progression to cirrhosis (as current phase 3 trials are set to demonstrate) a big step forward in reducing the duration of registrational trials will be possible. Finally, although counterintuitively, ALT reduction seemed to be slower than liver fat loss. This could mean that for certains drugs early assessment of ALT response (at 12 weeks in proof-of-concept trials) might miss real biochemical activity.

Whether resmetirom works better in patients with more pronounced hepatic hypothyroidism is unknown and most patients in this trial presumably had low rather than high normal TSH baseline levels. Also, the pharmacodynamics of resmetirom displayed major individual variability which impacted the magnitude of hepatic effects. Nonetheless, resmetirom establishes a new class of NASH drugs now moving into a large phase 3 trial with considerable excitement for investigators and patients. 
Conflicts of interest : I have received advisory board fees related to NASH treatments and NASH disease perception, awareness, and unmet needs from Genfit, Intercept, Galmed, Astra-Zeneca, Boehringer-Ingelheim, Madrigal (relating to disease awareness, patient stratification for adverse outcomes and hence need for pharmacotherapy, current medications used for NASH, physicians expectations for future NASH drugs, review of published data on phase 2 trials in NASH), Poxel, Allergan, Servier, Echosens, Coherus, Enanta, and Bristol-Myers-Squibb. I am principal investigator in NASH therapeutic trials: REGENERATE (Intercept); RESOLVE-IT (Genfit); ARREST (Galmed), and ARGON-1 (Enanta). 


\section{REFERENCES}

1. Ludwig U, Holzner D, Denzer C, Greinert A, Haenle MM, Oeztuerk S, et al. Subclinical and clinical hypothyroidism and non-alcoholic fatty liver disease: a cross-sectional study of a random population sample aged 18 to 65 years. BMC Endocr Disord. 2015; 15: 41.

2. Bril F, Kadiyala S, Portillo Sanchez P, Sunny NE, Biernacki D, Maximos M, et al. Plasma thyroid hormone concentration is associated with hepatic triglyceride content in patients with type 2 diabetes. Journal of Investigative Medicine. 2016; 64(1): 63-8.

3. Chung GE, Kim D, Kim W, Yim JY, Park MJ, Kim YJ, et al. Non-alcoholic fatty liver disease across the spectrum of hypothyroidism. Journal of Hepatology. 2012; 57(1): 150-6.

4. Bano A, Chaker L, Plompen EP, Hofman A, Dehghan A, Franco OH, et al. Thyroid Function and the Risk of Nonalcoholic Fatty Liver Disease: The Rotterdam Study. J Clin Endocrinol Metab. 2016; 101(8): 3204-11.

5. Xu L, Ma H, Miao M, Li Y. Impact of subclinical hypothyroidism on the development of nonalcoholic fatty liver disease: A prospective case-control study. Journal of Hepatology. 2012; 57(5): 1153-4.

6. Ferrandino G, Kaspari RR, Spadaro O, Reyna-Neyra A, Perry RJ, Cardone R, et al. Pathogenesis of hypothyroidism-induced NAFLD is driven by intra- and extrahepatic mechanisms. Proc Natl Acad Sci U S A. 2017; 114(43): E9172-E80.

7. Kim D, Kim W, Joo SK, Bae JM, Kim JH, Ahmed A. Subclinical Hypothyroidism and Low-Normal Thyroid Function Are Associated With Nonalcoholic Steatohepatitis and Fibrosis. Clin Gastroenterol Hepatol. 2018; 16(1): 123-31 e1.

8. Bohinc BN, Michelotti G, Xie G, Pang H, Suzuki A, Guy CD, et al. Repair-Related Activation of Hedgehog Signaling in Stromal Cells Promotes Intrahepatic Hypothyroidism. Endocrinology. 2014; 155(11): 4591-601.

9. Sinha RA, You S-H, Zhou J, Siddique MM, Bay B-H, Zhu X, et al. Thyroid hormone stimulates hepatic lipid catabolism via activation of autophagy. Journal of Clinical Investigation. 2012; 122(7): 2428-38.

10. Alonso-Merino E, Martín Orozco R, Ruíz-Llorente L, Martínez-Iglesias OA, Velasco-Martín JP, Montero-Pedrazuela A, et al. Thyroid hormones inhibit TGF- $\beta$ signaling and attenuate fibrotic responses. Proceedings of the National Academy of Sciences. 2016; 113(24): E3451-E60.

11. Taub R, Chiang E, Chabot-Blanchet M, Kelly MJ, Reeves RA, Guertin MC, et al. Lipid lowering in healthy volunteers treated with multiple doses of MGL-3196, a liver-targeted thyroid hormone receptor-beta agonist. Atherosclerosis. 2013; 230(2): 373-80.

12. Bril F, Barb D, Lomonaco R, Lai J, Cusi K. Change in hepatic fat content measured by MRI does not predict treatment-induced histological improvement of steatohepatitis. J Hepatol. 2019; in press. 